\title{
INFLUENCE OF UREA ADDITION ON PREPARATION AND ACIDIC PROPERTIES OF AMORPHOUS LANTHANUM PYROPHOSPHATE
}

\author{
Hiroaki Onoda $^{1^{*}}$, Yuya Ishima ${ }^{2}$, Hirokazu Nakayama $^{3}$, Isao Tanaka ${ }^{4}$ \\ (*Corresponding author: onoda@inm.res.titech.ac.jp)
}

\author{
${ }^{1}$ Division of Inorganic Materials Chemistry, Chemical Resources Laboratory, \\ 4259-R1-21, Nagatsuta, Midori-ku, Yokohama 226-8503, Japan \\ ${ }^{2}$ Department of Applied Chemistry, Faculty of Science and Engineering, Ritsumeikan University, 1-1-1, \\ Nojihigashi, Kusatsu, Shiga 525-8577, Japan \\ ${ }^{3}$ Kobe Pharmaceutical University, 4-19-1, Motoyamakita, Higashinada, Kobe, 658-8558, Japan. \\ ${ }^{4}$ Department of Materials Science and Engineering, Faculty of Engineering, Kyoto University, \\ Yoshida-Honmachi, Sakyo-ku, Kyoto 606-8501, Japan
}

Keywords: Lanthanum pyrophosphate, addition of urea, acidic properties

\begin{abstract}
The addition of urea was studied as one of the preparation methods for porous phosphate particles. Urea was added to the preparation of lanthanum pyrophosphate from lanthanum nitrate and sodium pyrophosphate solutions. The precipitations prepared in various concentration of urea and their thermal products were estimated about the chemical composition, powder and acidic properties. The addition of urea on preparation of lanthanum pyrophosphate produced the increase of about 10-20 nm-radius pores. The large amount of urea covered the pore of lanthanum pyrophosphate. The amount of included urea in lanthanum phosphate was estimated from $\mathrm{NH}_{3}$-TPD curves. The addition of urea did not improve the adsorption ratio of trimethylamine because of the balance between the remained urea and improvement of specific surface area.
\end{abstract}

(Received March 14, 2007; Accepted May 24, 2007)

\section{INTRODUCTION}

Phosphates have been used for ceramic materials, catalysts, adsorbent, fluorescent materials, dielectric substances, metal surface treatment, manure, detergent, food additives, fuel cells, pigments, etc. The catalytic and adsorptive properties of phosphates were affected from specific surface area [1-3]. To improve the functional properties, nano-porous phosphate, which has large specific surface area, is tried to be prepared $[4,5]$. The addition of urea and so on had some possibility to obtain large specific surface area in the fields of synthesis of inorganic materials [6-9]. Aluminum phosphates containing urea were obtained in aqueous solution [10,11]. By decomposition of urea, aluminum phosphate became to be porous material. Urea was considered to decompose in following equations.

$$
\mathrm{CO}\left(\mathrm{NH}_{2}\right)_{2}+\mathrm{H}_{2} \mathrm{O} \rightarrow \mathrm{CO}_{2}+2 \mathrm{NH}_{3}
$$

Phosphates are transformed to other forms of phosphates in hydrolysis and dehydration reactions at elevated temperatures. Polyphosphate, cyclophosphate, and ultraphosphate are included in a group of condensed phosphates. Polyphosphate has a chain structure in which the $\mathrm{PO}_{4}$ unit shares two oxygen atoms; cyclo-phosphate has a cyclic structure; and ultraphosphate has a network structure. These condensed phosphates had a possibility to have novel functional properties.

Lanthanum phosphate is interesting material as an additive for catalyst, solid state electrolyte, and so on. Rhabdophane-type lanthanum phosphate is able to be prepared in aqueous solution and transforms to monazite-type lanthanum phosphate by heating [12]. It is important to control the powder condition, such as porous, globular, and so on, of lanthanum phosphate. The addition of urea has the possibility to produce the functional powder and acidic properties, without the change of chemical composition. Acidic solid state materials are used as adsorbent for basic stinking gas.

There are ammonia, dihydrogen sulphide, trimethylamine, methylmercaptane, and so on in the group of stinking gas. Because ammonia and trimethylamine are basic compounds, these gases are possible to be removed with acidic adsorbent.

In previous work, lanthanum orthophosphates containing urea were prepared from lanthanum nitrate solution, phosphoric acid solution, and urea in various conditions [12]. The addition of urea had much influence on specific surface area, pore size distribution, particle shape and size of lanthanum phosphate prepared in aqueous solution, without the change of chemical composition. The amount of included urea in lanthanum phosphate was estimated from $\mathrm{NH}_{3}$-TPD curves. The adsorption of 
trimethylamine on lanthanum phosphate was improved by the addition of urea. The addition of urea in the preparation of phosphate is one of the useful and conventional methods for the design of functional materials.

In this work, lanthanum pyrophosphates, $\mathrm{La}_{4}\left(\mathrm{P}_{2} \mathrm{O}_{7}\right)_{3}$, containing urea were tried to be prepared from lanthanum nitrate solution, sodium pyrophosphate solution, and urea in various conditions. The obtained precipitation was estimated by thermogravimetry - differential thermal analysis, X-ray diffraction, Fourier transform infrared spectroscopy, and solid state nuclear magnetic resonance spectra. The powder properties of phosphate were studied from specific surface area, pore size distribution, particle size distribution, and scanning electron microscopy images. Furthermore, ammonia - temperature programmed desorption and adsorption of trimethylamine were measured to clarify the additional effects of urea on acidic properties of this phosphate.

\section{EXPERIMENTAL}

Sodium pyrophosphate, $\mathrm{Na}_{4} \mathrm{P}_{2} \mathrm{O}_{7}$, was synthesized by heating disodium hydrogenphosphate. $0.1 \mathrm{~mol} / \mathrm{l}$ of lanthanum nitrate solution was mixed to $0.1 \mathrm{~mol} / \mathrm{l}$ of sodium pyrophosphate solution in the molar ratio of $\mathrm{La} / \mathrm{P}=2 / 3$ and then stirred for 1 hour at room temperature. Urea was added in this sodium pyrophosphate solution to the prescribed concentration $(0.5$ or $1.5 \mathrm{~mol} / \mathrm{l})$ before the mixing. The precipitation was filtered off, washed with water, and dried. A part of the precipitations was dissolute in hydrochloric acid solution. The ratios of nickel, lanthanum, phosphorus in the precipitations were calculated from Inductivity Coupled Plasma Atomic Emission Spectrometry (ICP) results of these solutions. The ICP estimation was measured with Shimadzu ICPS-8000.

The thermal behavior of these materials was analyzed by thermogravimetry - differential thermal analyses (TG-DTA), X-ray diffraction (XRD), Fourier transform infrared spectroscopy (FT-IR), and solid state nuclear magnetic resonance (NMR). TG and DTA curves were measured with a Shimadzu DTA-60/60H at a heating rate of $10{ }^{\circ} \mathrm{C} / \mathrm{min}$ under air condition. Thermal analyses were carried out at $10^{\circ}$ $\mathrm{C} / \mathrm{min}$. Samples were heated at 100, 250, 400, and $700{ }^{\circ} \mathrm{C}$ for 1 hour. XRD patterns were recorded on a Rigaku Denki RINT 2000M X-Ray diffractometer using monochromated $\mathrm{CuK} \alpha$ radiation. The IR spectra were recorded on a Shimadzu FT-IR spectrometer, FT-IR8600, with a $\mathrm{KBr}$ disk method. Solid ${ }^{31} \mathrm{P}$ MAS NMR spectra were obtained with JEOL GSX-270W using $85 \% \mathrm{H}_{3} \mathrm{PO}_{4}$ as an external standard.
Specific surface area and pore size distribution of phosphates were calculated from the amount of nitrogen gas adsorbed at the temperature of liquid nitrogen by BET and DH methods with Belsorp mini from BEL JAPAN, INC. Particle size distribution of these materials was measured with laser diffraction / scattering particle size distribution HORIBA LA-910. Furthermore, scanning electron microscopy (SEM) images were observed using VE8800 from Keyence Co. Ltd.

Acidic properties (acidic strength and amount of acidic sites) were examined by ammonia temperature programmed desorption ( $\left.\mathrm{NH}_{3}-\mathrm{TPD}\right)$ using TPD-1-AT from BELJAPAN, INC. First, for the estimation of the amount of included urea in lanthanum phosphate (equation (1)), the samples were measured form 100 to $550{ }^{\circ} \mathrm{C}$ without the adsorption of ammonia (a). Second, the samples were examined with the adsorption of ammonia for 1 hour before measurement (b). The acidic strength and amount of acidic sites were estimated from the difference between (a) and (b). The acid strength was from the desorption temperature, and the amount of acidic sites was from the volume of ammonia desorption.

The adsorption of trimethylamine gas on phosphates was estimated at room temperature. The $0.01 \mathrm{~g}$ of samples was placed in a gas bag $\left(3000 \mathrm{~cm}^{3}\right)$ of polyethylene, which was then filled with trimethylamine gas (15.9 ppm). The concentration of trimethylamine gas was determined with a Kitagawa gas detector after the standing for 10 minutes.

\section{RESULTS AND DISCUSSION}

\subsection{Preparation of phosphate materials}

FIGURE 1 shows DTA curves of samples prepared in various urea concentrations. Sample prepared without urea had an endothermic peak at 80 ${ }^{\circ} \mathrm{C}$, due to the volatilization of water, in DTA curve (FIGURE 1(a)). By the addition of urea, an exothermic peak appeared from 250 to $280{ }^{\circ} \mathrm{C}$ (FIGURE 1(b)(c)). Urea was considered to decompose to ammonia and carbon dioxide and volatilized at this range of temperature. The heating rate was too fast to confirm the formation of biuret and cyanuric acid. It is difficult to clear the reason why the addition of urea produces the exothermic peak in DTA curve, from the previous results of aluminum orthophosphate [10], polyphosphate [11], and lanthanum orthophosphate [12].

FIGURE 2 shows TG curves of lanthanum pyrophosphates prepared in various urea concentrations. Samples prepared with urea had three steps of weight loss (FIGURE 2 (b)(c)). First one was to $130{ }^{\circ} \mathrm{C}$, second one was from 130 to $280^{\circ} \mathrm{C}$, the 


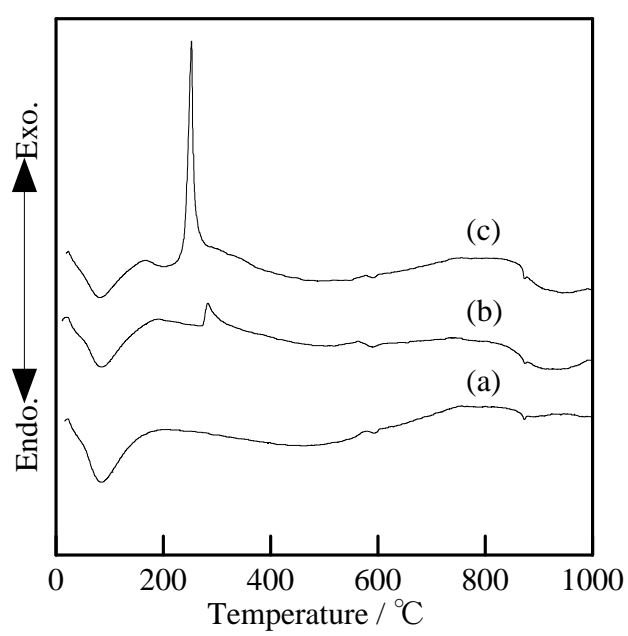

FIGURE 1 DTA curves of lanthanum pyrophosphates prepared in various urea concentrations, (a) $0 \mathrm{~mol} / \mathrm{l}$, (b) $0.5 \mathrm{~mol} / \mathrm{l}$, and (c) $1.5 \mathrm{~mol} / \mathrm{l}$.

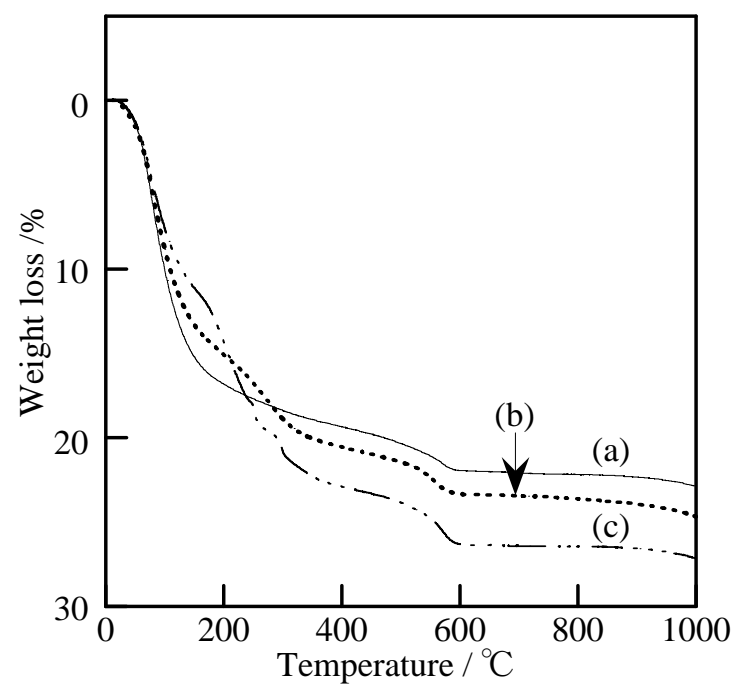

FIGURE 2 TG curves of lanthanum pyrophosphates prepared in various urea concentrations, (a) $0 \mathrm{~mol} / \mathrm{l}$, (b) $0.5 \mathrm{~mol} / \mathrm{l}$, and (c) $1.5 \mathrm{~mol} / \mathrm{l}$.

last one was over $280{ }^{\circ} \mathrm{C}$. These were due to the volatilization of water, the decomposition of urea, and phase transition of phosphate described in following.

FIGURE 3 shows XRD patterns of sample prepared without urea and then heated at several temperatures. All samples without heating were amorphous from XRD analyses. Samples heated at $400{ }^{\circ} \mathrm{C}$ had the weak peaks of monazite-type $\mathrm{LaPO}_{4}$. All samples at $600{ }^{\circ} \mathrm{C}$ had the peaks of the lanthanum orthophosphate (JCPDS Card No. 32-0199). The urea concentration had less influence on XRD patterns.

FIGURE 4 shows IR spectra of samples prepared without urea and heated at several temperatures. Sample prepared in this work had some water and nitrate. These water and nitrate volatilized by heating.

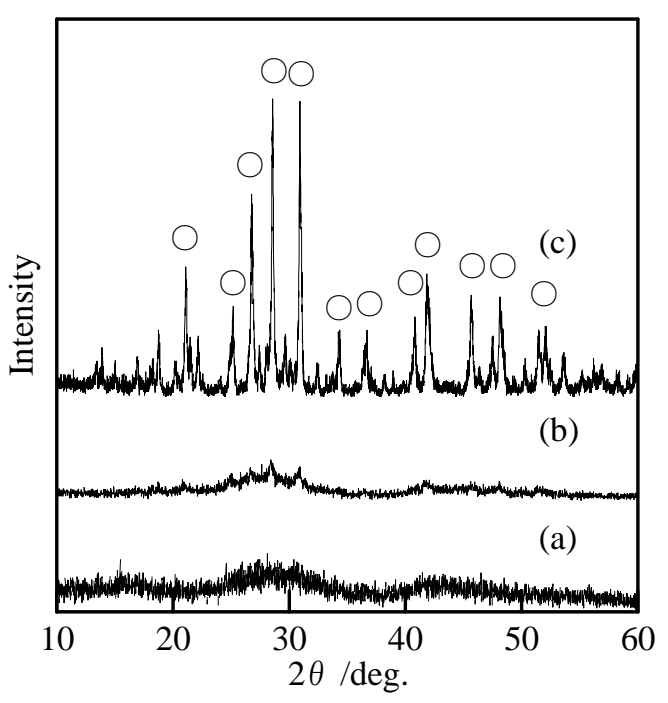

FIGURE 3 XRD patterns of samples prepared without urea and heated at several temperatures, (a) R. T., (b) $400{ }^{\circ} \mathrm{C}$, (c) $600{ }^{\circ} \mathrm{C}, \bigcirc ; \mathrm{LaPO}_{4}$.

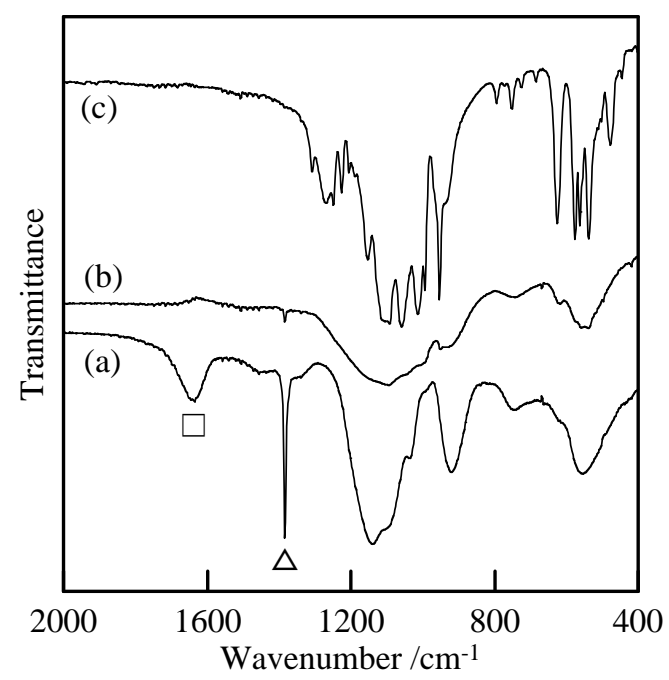

FIGURE 4 IR spectra of samples prepared without urea and heated at several temperatures, (a) R. T., (b) $400{ }^{\circ} \mathrm{C}$, (c) $700{ }^{\circ} \mathrm{C}$, $\square$; $\mathrm{H}_{2} \mathrm{O}$ and $\triangle$; $\mathrm{NO}_{3}^{-}$.

The chemical composition of materials changed from pyrophosphate to orthophosphate.

FIGURE 5 shows NMR spectra of samples prepared with and without urea. Sample prepared without urea had two peaks at $\delta=-0.28$ and -3.30 ppm (FIGURE 5 (a)). These peaks were due to orthophosphate and pyrophosphate, respectively [13]. A part of pyrophosphate was decomposed to orthophosphate in preparation process. Sample prepared with urea had smaller ratio of pyrophosphate (FIGURE 5(b)). The addition of urea promoted the decomposition of pyrophosphate. These phenomena were also observed in thermal products at 

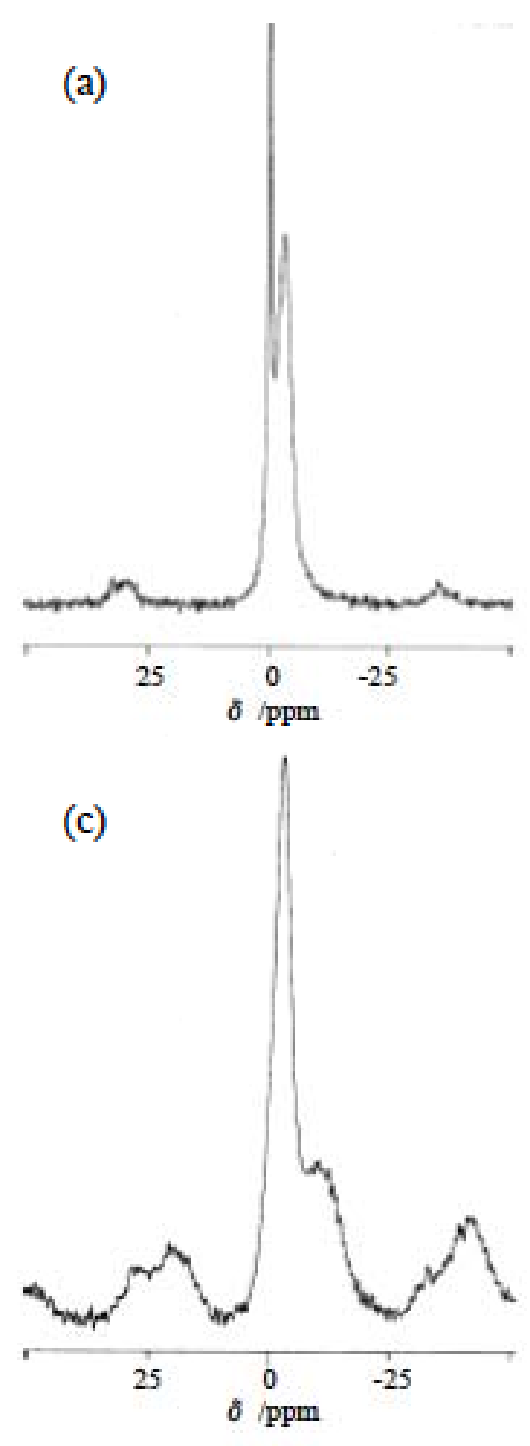
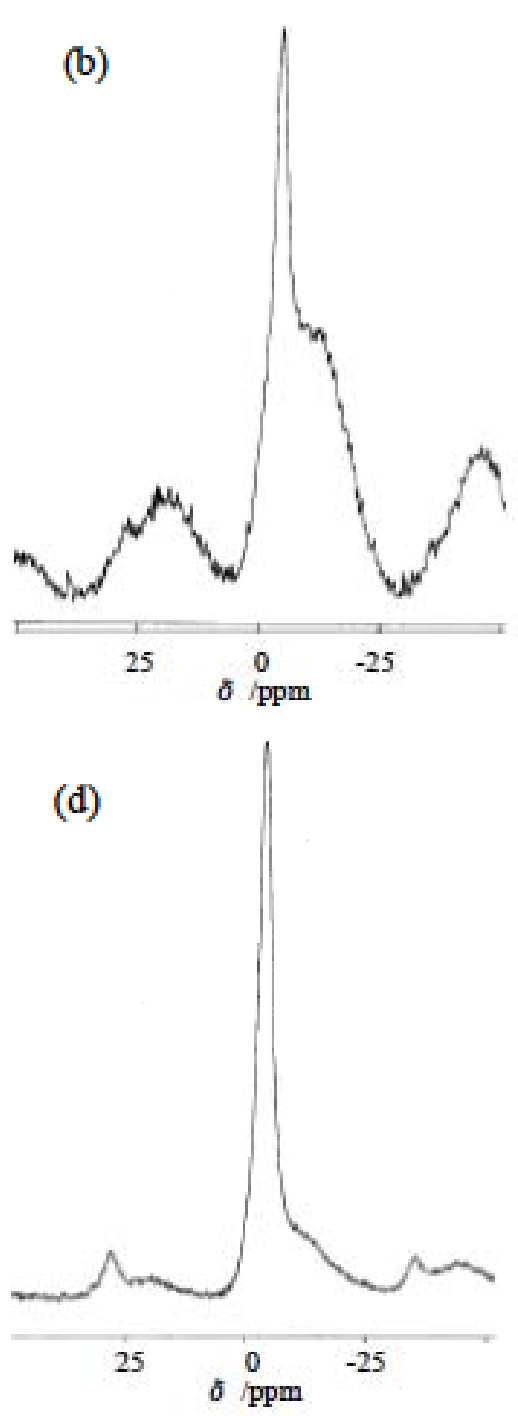

FIGURE 5 Solid ${ }^{31} \mathrm{P}$ MAS NMR spectra of samples, (a) without urea, R.T., (b) with $0.5 \mathrm{~mol} / \mathrm{l}$ of urea, R. T., (c) without urea, $400{ }^{\circ} \mathrm{C}$, (d) with $0.5 \mathrm{~mol} / \mathrm{l}$ of urea, $400{ }^{\circ} \mathrm{C}$.

$400{ }^{\circ} \mathrm{C}$ (FIGURE 5(c) and (d)). Lanthanum pyrophosphate transformed to orthophosphate by heating.

TABLE 1 shows ICP results of precipitations. The $\mathrm{La} / \mathrm{P}$ molar ratio was between lanthanum pyrophosphate $(\mathrm{La} / \mathrm{P}=0.667)$ and orthophosphate $(\mathrm{La} / \mathrm{P}=1.000)$.

TABLE 1 La/P molar ratio of precipitations

\begin{tabular}{cc}
\hline Urea concentration/mol $\cdot \mathrm{l}^{-1}$ & $\mathrm{La} / \mathrm{P}$ \\
\hline 0 & 0.728 \\
0.5 & 0.740 \\
1.5 & 0.779 \\
\hline
\end{tabular}

\subsection{Powder properties of phosphate materials}

TABLE 2 shows specific surface area of phosphates. Specific surface area of materials became smaller by the large amount of urea addition.

TABLE 2 Specific surface area of lanthanum pyrophosphate prepared in various condition $/ \mathrm{m}^{2} \cdot \mathrm{g}^{-1}$

\begin{tabular}{cccc}
\hline Urea concentration & \multicolumn{3}{c}{ Temperature $/{ }^{\circ} \mathrm{C}$} \\
\hline$/ \mathrm{mol} \cdot \mathrm{l}^{-1}$ & 100 & 250 & 400 \\
\hline 0 & 51.6 & 25.7 & 49.6 \\
0.5 & 54.9 & 47.7 & 49.4 \\
1.5 & 19.9 & 20.3 & 26.1 \\
\hline
\end{tabular}


FIGURE 6 shows pore size distribution of phosphates heated at $400{ }^{\circ} \mathrm{C}$. These samples were mainly orthophosphate. Sample prepared without urea had little pores (FIGURE 6(a)). A little addition of urea increased about 10-20 nm pores (FIGURE 6(b)). However, the larger amount of urea was considered to cover the pore of phosphate (FIGURE 6(c)). Urea in phosphate materials decomposed incompletely by heating at $400{ }^{\circ} \mathrm{C}$. $1.5 \mathrm{~mol} / \mathrm{l}$ of urea was not suitable to obtain the porous materials.

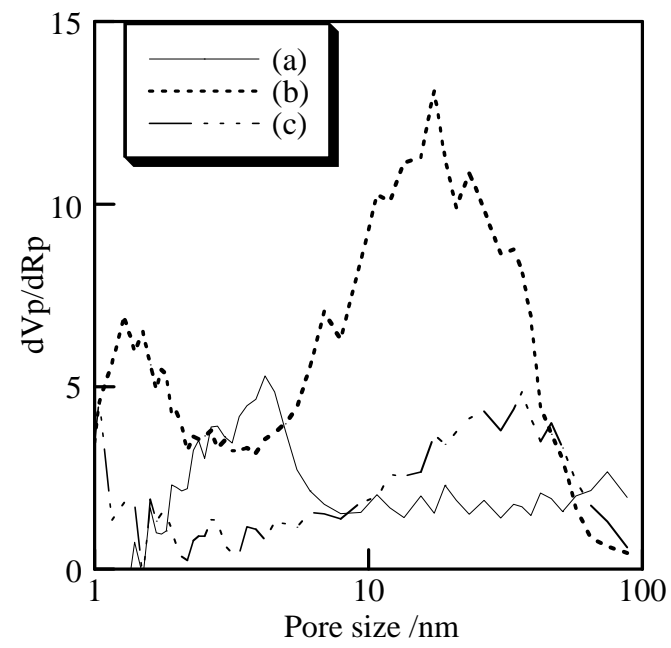

FIGURE 6 Pore size distribution of samples prepared in various urea concentrations and heated at $400^{\circ} \mathrm{C}$, (a) $0 \mathrm{~mol} / \mathrm{l}$, (b) $0.5 \mathrm{~mol} / \mathrm{l}$, and (c) 1.5 $\mathrm{mol} / \mathrm{l}$.

FIGURE 7 shows particle size distribution of phosphates heated at $400{ }^{\circ} \mathrm{C}$. The major parts of particles were from 3 to 200 micrometer. The addition of urea had less influence on particle size of

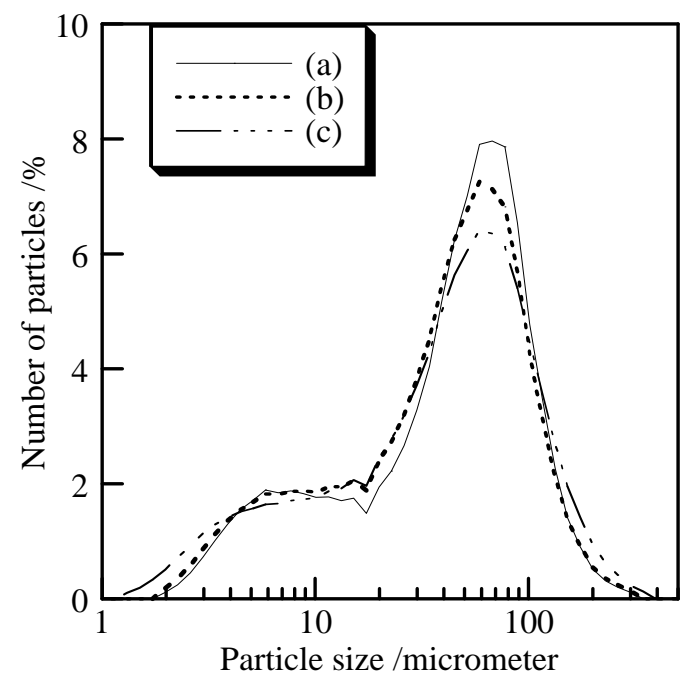

FIGURE 7. Particle size distribution of samples prepared in various urea concentrations and heated at $400^{\circ} \mathrm{C}$, (a) $0 \mathrm{~mol} / \mathrm{l}$, (b) $0.5 \mathrm{~mol} / \mathrm{l}$, and (c) $1.5 \mathrm{~mol} / \mathrm{l}$. lanthanum pyrophosphate. Further, all samples had no specified shape from SEM images.

\subsection{Acidic properties of phosphate materials}

The acidic properties are important for some application of materials, for example, adsorbent, catalyst, and so on. In general, $\mathrm{NH}_{3}$-TPD was measured after ammonia adsorption for the estimation of acidic properties on materials. Because ammonia was adsorbed on acidic sites of phosphate surface, the acidic strength and amount of acidic sites were studied from the desorption temperature and the volume of ammonia, respectively. However, samples in this work could not be discussed simply. Because urea decomposed to ammonia and carbon dioxide, the normal desorption curve was due to total amount of two kinds of ammonia, one was based on acidic sites, and another was from urea. In this work, to separate this ammonia, the ammonia-TPD was measured without the adsorption of ammonia as pre-measurement. This profile was due to the decomposition of urea. The difference between this curve and general one was corresponding to the acidic sites on phosphate surface.

FIGURE 8 shows ammonia-TPD profiles of samples prepared without urea. Sample prepared without urea had little desorption of ammonia only by heating (FIGURE 8(a)). The normal TPD curve (FIGURE 8(b)) had small peak below $300{ }^{\circ} \mathrm{C}$. The difference between FIGURE 8(a) and (b) was corresponding to the acidic strength and amount of acidic sites of lanthanum pyrophosphate.

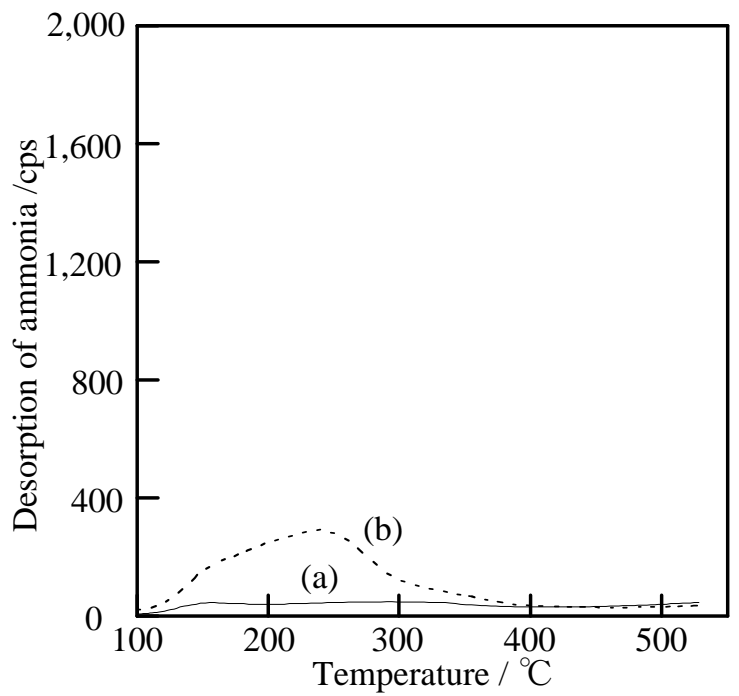

FIGURE $8 \quad \mathrm{NH}_{3}$-TPD profiles of lanthanum pyrophosphate prepared without urea and heated at $100^{\circ} \mathrm{C}$, (a) without $\mathrm{NH}_{3}$ adsorption before measurement and (b) with.

FIGURE 9 shows ammonia-TPD profiles of samples prepared with $0.5 \mathrm{~mol} / \mathrm{l}$ of urea. TPD profile without pretreatment (ammonia adsorption) had the 
peak at $240{ }^{\circ} \mathrm{C}$ due to the decomposition of included urea (FIGURE 9(a)). This temperature was related with the second step of weight loss in TG curve (FIGURE 2(b)). The TPD curve measured with the pretreatment (ammonia adsorption) indicated large amount of ammonia desorption at 200-350 ${ }^{\circ} \mathrm{C}$ (FIGURE 9(b)). The amount of acidic sites increased by $0.5 \mathrm{~mol} / \mathrm{l}$ of urea addition. TABLE 3 shows amount of acidic sites of lanthanum pyrophosphates. The amount of included urea was estimated from the area (a), because one molar of urea produced two molar of ammonia (equation (1)). Sample prepared with $0.5 \mathrm{~mol} / \mathrm{l}$ of urea had larger amount of acidic sites than others (TABLE 3 (b)-(a)). Too much concentration of urea decreased the amount of acidic sites, because urea decomposed and volatilized incompletely.

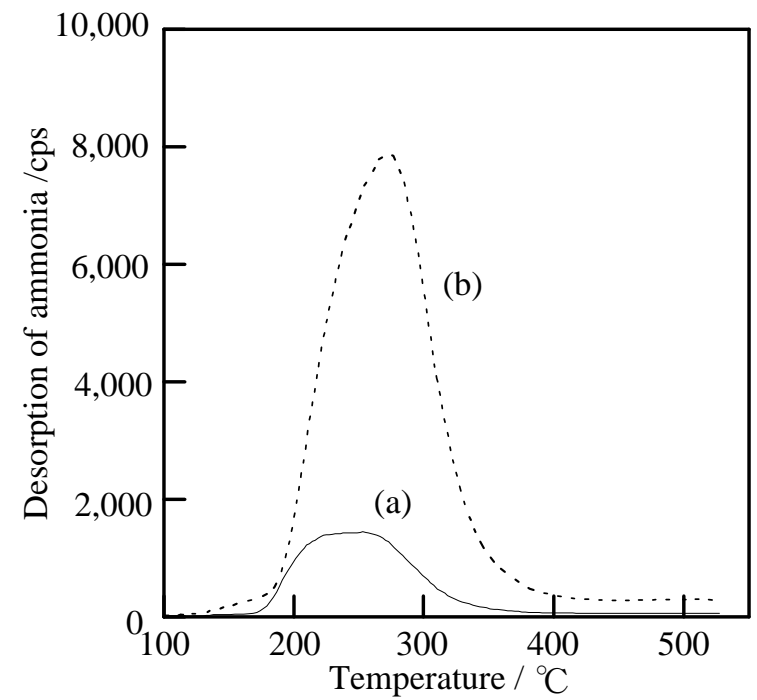

FIGURE $9 \quad \mathrm{NH}_{3}$-TPD profiles of lanthanum pyrophosphate prepared with $0.5 \mathrm{~mol} / \mathrm{l}$ of urea and heated at $100^{\circ} \mathrm{C}$, (a) without $\mathrm{NH}_{3}$ adsorption before measurement and (b) with.

TABLE 3 Amount of $\mathrm{NH}_{3}$ desorption on lanthanum pyrophosphates

\begin{tabular}{cccc}
\hline \multicolumn{3}{l}{ Urea concentration } & $\mathrm{NH} 3$ \\
$\mathrm{~mol} \cdot \mathrm{l}^{-1}$ & (a) & (b) & (b)-(a) \\
\hline 0 & 0.07 & 0.22 & 0.15 \\
0.5 & 1.08 & 4.90 & 3.82 \\
1.5 & 2.47 & 2.59 & 0.12 \\
\hline
\end{tabular}

(a) without $\mathrm{NH}_{3}$ adsorption, (b) with $\mathrm{NH}_{3}$ adsorption.

FIGURE 10 shows adsorption ratio of trimethylamine on phosphate materials. The adsorption ratio became small by heating. The addition of urea did not improve the adsorption ratio of trimethylamine because of the balance between the remained urea (decrease of acidic sites) and improvement of specific surface area. The addition of urea is useful method to obtain porous materials, however not suitable way to improve the adsorption of basic gas.

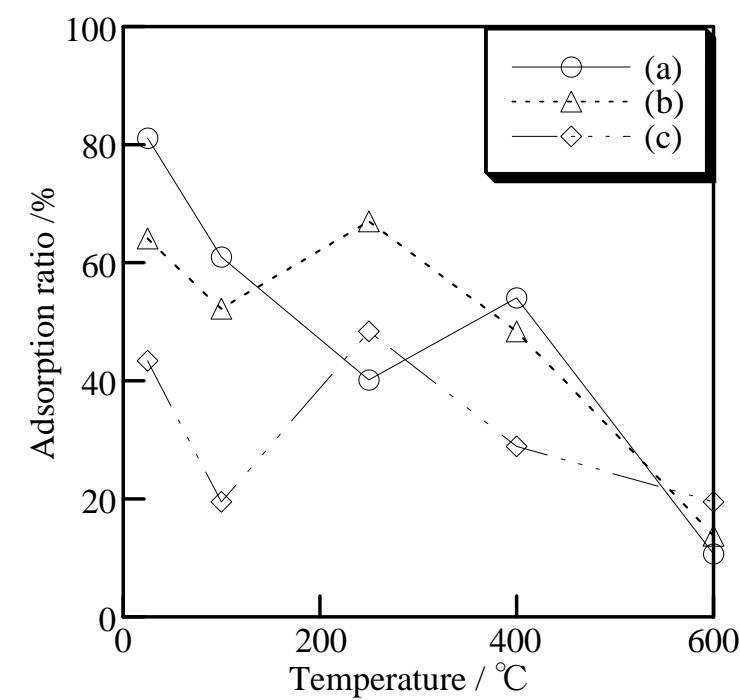

FIGURE 10 Adsorption of trimethylamine on samples prepared in various urea concentrations, (a) 0 $\mathrm{mol} / \mathrm{l}$, (b) $0.5 \mathrm{~mol} / \mathrm{l}$, and (c) $1.5 \mathrm{~mol} / \mathrm{l}$.

\section{CONCLUSION}

The addition of urea promoted the transition from pyrophosphate to orthophosphate. Lanthanum pyrophosphate changed to orthophosphate also by heating. 10-20 nm-radius of pores increased by the small addition of urea. The large amount of urea covered the pore of phosphate material. The amount of included urea in phosphate was estimated from $\mathrm{NH}_{3}$-TPD curves. The addition of urea did not improve the adsorption ratio of trimethylamine because of the balance between the remained urea and improvement of specific surface area. Further investigation was required for the design of functional materials. The addition of urea has some possibility to obtain porous materials and to improve the acidic properties of phosphate materials.

\section{REFERENCES}

1. H. Onoda, H. Nariai, A. Moriwaki, H. Maki, I. Motooka, J. Mater. Chem., 12(6), 1754 (2002).

2. H. Onoda, T. Ohta, J. Tamaki, K. Kojima, Appl. Catal. A, 288(1-2), 98 (2005).

3. H. Onoda, T. Ohta, J. Tamaki, K. Kojima, H. Nariai, Mater. Chem. Phys., 96(1), 163 (2006).

4. D. Gao, Q. Gao, Microporous Mesoporous Mater., 85, 365 (2005).

5. V. A. R. Monteiro, E. F. Sanza, M. M. M. Azevedo, 
F. Galembeck, J. Coll. Interf. Sci., 217, 237 (1999).

6. K. Kandori, N. Ikegami, A. Yasukawa, T. Ishikawa, J. Coll. Interf. Sci., 182, 425 (1996).

7. T. Hernadez, C. Bautista, P. Martin, Mater. Chem. Phys., 92, 366 (2005).

8. A. Tarafdar, S. Biswas, N. K. Pramanik, P. Pramanik, Microporous Mesoporous Mater., 89, 204 (2006).

9. C. Shu, W. Yanwei, L. Hong, P. Zhengzheng, Y. Kangde, Ceramics International, 31, 135 (2005).

10. H. Onoda, S. Ukita, A. Hayashi, A. Takenaka, K. Kojima, Phosphorus Res. Bull., 19, 209 (2005).

11. H. Onoda, M. Kohno, K. Kojima, A. Takenaka, I. Tanaka, Mater. Chem. Phys., submitted.

12. H. Onoda, K. Taniguchi, I. Tanaka, Microporous Mesoporous Mater., accepted.

13. K. Amezawa, H. Maekawa, Y. Tomii, N. Yamamoto, Solid State Ionics, 145, 233 (2001). 